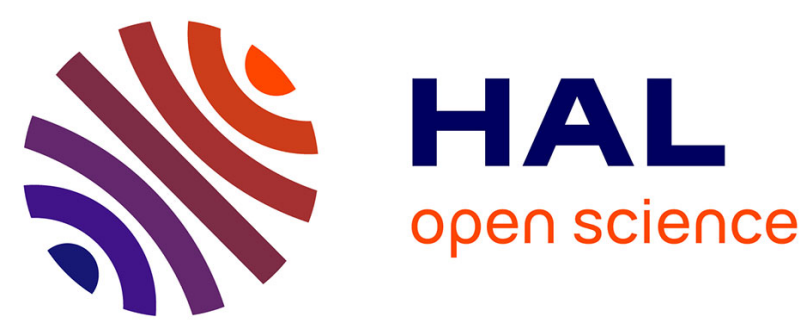

\title{
In Situ Transmission Electron Microscopy Analysis of Aluminum-Germanium Nanowire Solid-State Reaction
}

Khalil El Hajraoui, Minh Anh Luong, Eric Robin, Florian Brunbauer, Clemens Zeiner, Alois Lugstein, Pascal Gentile, Jean-Luc Rouvière, M. den Hertog

\section{- To cite this version:}

Khalil El Hajraoui, Minh Anh Luong, Eric Robin, Florian Brunbauer, Clemens Zeiner, et al.. In Situ Transmission Electron Microscopy Analysis of Aluminum-Germanium Nanowire Solid-State Reaction. Nano Letters, 2019, 19 (5), pp.2897-2904. 10.1021/acs.nanolett.8b05171 . hal-02910070

\section{HAL Id: hal-02910070 https://hal.science/hal-02910070}

Submitted on 31 Jul 2020

HAL is a multi-disciplinary open access archive for the deposit and dissemination of scientific research documents, whether they are published or not. The documents may come from teaching and research institutions in France or abroad, or from public or private research centers.
L'archive ouverte pluridisciplinaire HAL, est destinée au dépôt et à la diffusion de documents scientifiques de niveau recherche, publiés ou non, émanant des établissements d'enseignement et de recherche français ou étrangers, des laboratoires publics ou privés. 


\title{
In Situ Transmission Electron Microscopy Analysis of Aluminum- Germanium Nanowire Solid-State Reaction
}

\author{
Khalil El hajraoui, ${ }^{\dagger, \uparrow}$ Minh Anh Luong, ${ }^{\dagger, \S \odot ~ E r i c ~ R o b i n, ~}{ }^{\dagger, \S}$ Florian Brunbauer, ${ }^{\dagger}$ Clemens Zeiner,

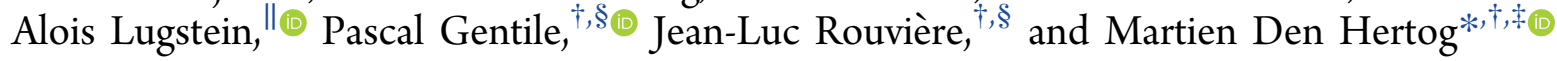 \\ ${ }^{\dagger}$ Université Grenoble Alpes, F-38000 Grenoble, France \\ ${ }^{\ddagger}$ CNRS, Institut NEEL, F-38000 Grenoble, France \\ ${ }^{\S}$ CEA, INAC, F-38000 Grenoble, France \\ "Institute for Solid State Electronics, Vienna University of Technology, Floragasse 7, 1040 Vienna, Austria
}

Supporting Information

\begin{abstract}
To fully exploit the potential of semiconducting nanowires for devices, high quality electrical contacts are of paramount importance. This work presents a detailed in situ transmission electron microscopy (TEM) study of a very promising type of NW contact where aluminum metal enters the germanium semiconducting nanowire to form an extremely abrupt and clean axial metal-semiconductor interface. We study this solid-state reaction between the

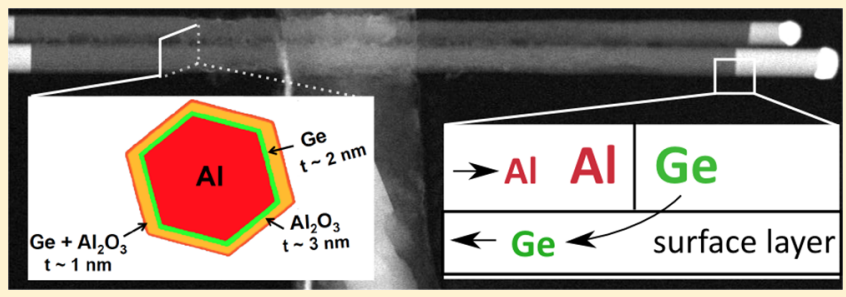
aluminum contact and germanium nanowire in situ in the TEM using two different local heating methods. Following the reaction interface of the intrusion of $\mathrm{Al}$ in the Ge nanowire shows that at temperatures between 250 and $330{ }^{\circ} \mathrm{C}$ the position of the interface as a function of time is well fitted by a square root function, indicating that the reaction rate is limited by a diffusion process. Combining both chemical analysis and electron diffraction we find that the $\mathrm{Ge}$ of the nanowire core is completely exchanged by the entering $\mathrm{Al}$ atoms that form a monocrystalline nanowire with the usual face-centered cubic structure of $\mathrm{Al}$, where the nanowire dimensions are inherited from the initial Ge nanowire. Model-based chemical mapping by energy dispersive X-ray spectroscopy (EDX) characterization reveals the three-dimensional chemical cross-section of the transformed nanowire with an $\mathrm{Al}$ core, surrounded by a thin pure Ge $(\sim 2$ $\mathrm{nm}), \mathrm{Al}_{2} \mathrm{O}_{3}(\sim 3 \mathrm{~nm})$, and Ge containing $\mathrm{Al}_{2} \mathrm{O}_{3}(\sim 1 \mathrm{~nm})$ layer, respectively. The presence of Ge containing shells around the $\mathrm{Al}$ core indicates that Ge diffuses back into the metal reservoir by surface diffusion, which was confirmed by the detection of Ge atoms in the $\mathrm{Al}$ metal line by EDX analysis. Fitting a diffusion equation to the kinetic data allows the extraction of the diffusion coefficient at two different temperatures, which shows a good agreement with diffusion coefficients from literature for selfdiffusion of Al.
\end{abstract}

KEYWORDS: Ge nanowire, solid state reaction, in situ transmission electron microscopy, energy dispersive X-ray spectroscopy, aluminum contact, diffusion

T $\mathrm{n}$ the last decades, many devices based on semiconducting nanowires (NWs) have been proposed in different research fields ranging from electronics ${ }^{1}$ and optoelectronics ${ }^{2}$ to energy conversion $^{3}$ and spintronics. ${ }^{4}$ However, one of the important factors that has been reported to limit the efficiency of these different devices is the contact quality between the metal and the semiconductor NW. To allow successful incorporation of these semiconducting NWs in nanoelectronics applications, low Ohmic resistance contacts need to be achieved, potentially using a silicidation process in $\mathrm{Si}$, or germanide process in $\mathrm{Ge}$, to efficiently inject and extract current from the device. A germanide is an intermetallic compound formed after a solidstate reaction between a metal and germanium, activated by a thermal anneal. The aim of the germanide phase is to lower the electrical contact resistance between the source/drain and channel. Hence, many studies ${ }^{5-24}$ have achieved electrical contacts between silicide or germanide phases and semi- conductor NW systems either using $\mathrm{Si} \mathrm{NWs}, \mathrm{Ni}-\mathrm{Si}, \mathrm{Pt}-\mathrm{Si}$, $\mathrm{Co}-\mathrm{Si}, \mathrm{Pd}-\mathrm{Si}, \mathrm{Ti}-\mathrm{Si}$, and $\mathrm{Cu}-\mathrm{Si}$, or with $\mathrm{Ge} \mathrm{NWs}, \mathrm{Ni}-\mathrm{Ge}$, $\mathrm{Cu}-\mathrm{Ge}, \mathrm{Al}-\mathrm{Ge}$, and $\mathrm{Mn}-\mathrm{Ge}$, revealing interesting electrical contact properties and a versatile potential for applications in new nanoelectronic devices.

In contrast to these studies on intermetallic phases, we have found previously that in the $\mathrm{Al}-\mathrm{Ge}$ system no intermetallic phase is formed; the $\mathrm{Al}$ replaces the $\mathrm{Ge}^{25}$ The $\mathrm{Al}-\mathrm{Ge}$ combination is of high interest both due to the high mobility of $\mathrm{Ge}$ and because of the superconductivity of $\mathrm{Al}$ at low temperature. In this paper, we present an in situ transmission electron microscopy (TEM) study of the $\mathrm{Al}-\mathrm{Ge}$ exchange mechanism. Being able to follow the reaction kinetics in real

Received: December 27, 2018

Revised: $\quad$ March 13, 2019

Published: March 25, 2019 

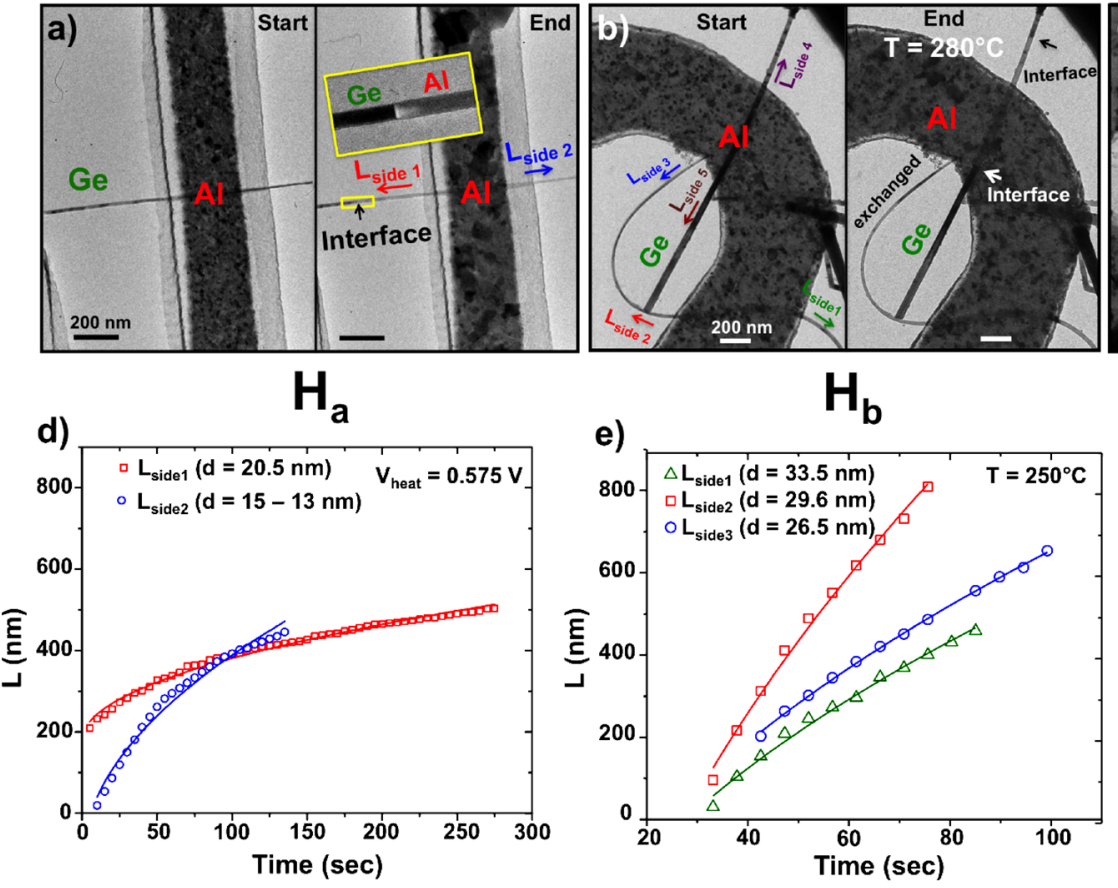

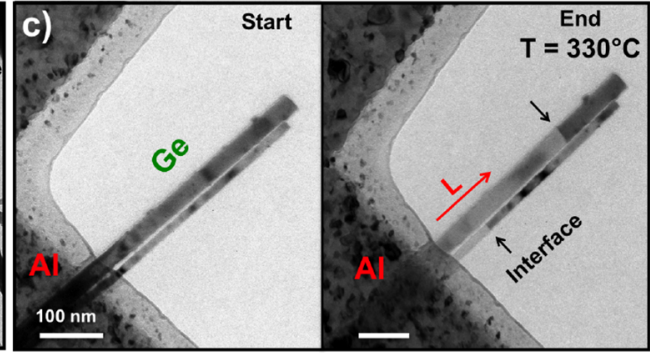

f)

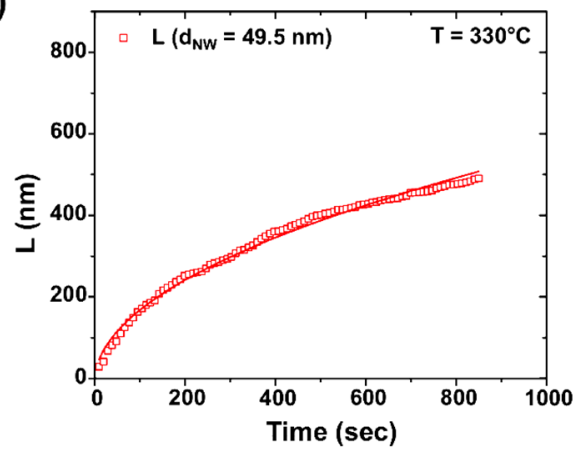

Figure 1. In situ aluminum-germanium propagation experiments using either in situ Joule heating $H_{\mathrm{a}}$ or $H_{\mathrm{b}}$. (a) TEM image showing the sample heated using in situ $H_{a}$; the two sides have different NW diameter. The inset shows a zoom on the interface after heating. (b,c) TEM images of in situ heating experiments $H_{\mathrm{b}}$ at two different temperatures: $250{ }^{\circ} \mathrm{C}$ and $330{ }^{\circ} \mathrm{C}$, respectively. (d) The length of transformed segment versus time at $\Delta V=0.575 \mathrm{~V}$ using in situ $H_{\mathrm{a}}$ for both opposite propagation directions $L_{\text {side1 }}$ (red open square; fit (red line)) and $L_{\text {side2 }}($ blue open circle; fit (blue line)). (e,f) The length of the transformed segment versus time at two different temperatures $250{ }^{\circ} \mathrm{C}$ and $330{ }^{\circ} \mathrm{C}$. (e) The length of the segment versus time at $250{ }^{\circ} \mathrm{C}$ in the curved $\mathrm{NW} L_{\text {side1 }}$ (red open triangle and fit (red line)), $L_{\text {side2 }}$ (green open square and fit (green line)) and $L_{\text {side3 }}($ blue open circle and fit (blue line)). (f) The length of the transformed segment at $330^{\circ} \mathrm{C}$ on the larger diameter $\mathrm{NW}$ versus time (red open square and fit (red line)). The profiles in $\mathrm{d}-\mathrm{f}$ are fit with eq 1 .

time at nanometer length scales is of crucial importance to understand such diffusion phenomena, especially since we have observed that often the propagation does not start at the same time in different NWs on the same sample, the propagation can suddenly stop entirely or proceed with large jumps. All this information is lost if only ex situ analysis is used. Furthermore, we present three-dimensional chemical characterization of the formed $\mathrm{Al} \mathrm{NW}$ that unveils the formation of a core-shell structure and allows one to understand the diffusion mechanism of $\mathrm{Al}$ in a $\mathrm{Ge} \mathrm{NW}$. In the following, we will focus on the solid-state reaction between an $\mathrm{Al}$ metal and a $\mathrm{Ge}$ NW, carried out in situ in a TEM, allowing the formation of a metal-semiconductor-metal heterostructure within a NW, either by using a very localized Joule heating in a metal strip deposited on the NW, or by using a membrane-substrate Joule heating. In this latter case, a current is passed through a buried metal heating spiral, leading to a more conventional situation where the entire sample is heated. The first method is referred to as direct Joule heating $H_{\mathrm{a}}$ and the second method is referred to as membrane-substrate Joule heating $H_{\mathrm{b}}$. The two heating techniques are compared and we can estimate diffusion constants by following the position of the reaction interface as a function of time.

Experimental Methods. The NWs used in these experiments were both $n$-doped and undoped Ge NWs, synthesized via the Au-assisted vapor liquid solid (VLS) process along the $\mathrm{Ge}\langle 111\rangle$ growth direction with diameters ranging from 10 to $150 \mathrm{~nm} .{ }^{26}$ Ge NWs were dispersed in ethanol using ultrasonic vibrations. The solution was drop casted on the membranes to disperse the Ge NWs. The Ge NWs were dispersed on two different silicon nitride $\left(\mathrm{Si}_{3} \mathrm{~N}_{4}\right)$ membranes: a commercial heater chip calibrated in temperature from DENSsolutions ${ }^{27}$ and uncalibrated homemade membranes with a $50 \mathrm{~nm}$ thick $\mathrm{Si}_{3} \mathrm{~N}_{4}$ layer on a $300 \mu \mathrm{m} \mathrm{Si}$ frame. The fabrication process is described in den Hertog et al. ${ }^{28}$ On the latter membranes, after dispersion of Ge NWs, two parallel metal lines are defined using electron beam lithography on a single Ge NW. This process is described in El hajraoui et al. ${ }^{29}$ and the metal was deposited by sputtering followed by electron beam induced metal evaporation.

The commercial heater chip contains a buried heating spiral in a $\mathrm{Si}_{3} \mathrm{~N}_{4}$ membrane allowing temperature-calibrated Joule heating. On these substrates, we dispersed Ge NWs on $20 \mathrm{~nm}$ thick $\mathrm{Si}_{3} \mathrm{~N}_{4}$ windows that are present at the center of the chip next to the heating spiral. These NWs were contacted on one side with an $\mathrm{Al}$ metal line providing the $\mathrm{Al}$ reservoir. Most heating experiments were carried out in situ on a TEM Philips CM300 working at $100 \mathrm{kV}$ equipped with a CMOS camera from TVIPS using a DENSsolutions double-tilt 6-contact biasing sample holder. ${ }^{27}$ An acceleration voltage below $150 \mathrm{kV}$ was used to avoid knock-on damage, creation of vacancies, and related modifications of electrical and diffusion properties. Structural characterization of different samples was performed posterior to the heating experiments or ex situ using the same microscope at $300 \mathrm{kV}$. Conventional electron beam diffraction was used with the aim of determining the crystalline structure of the transformed segment.

Chemical characterization was carried out ex situ in a state of the art FEI Osiris or probe corrected Titan Themis (at 200 $\mathrm{kV}$ ), equipped with four silicon drift detectors using an ultranarrow gap Fischione tomography sample holder, which allows a large solid angle for signal detection. The Themis was 

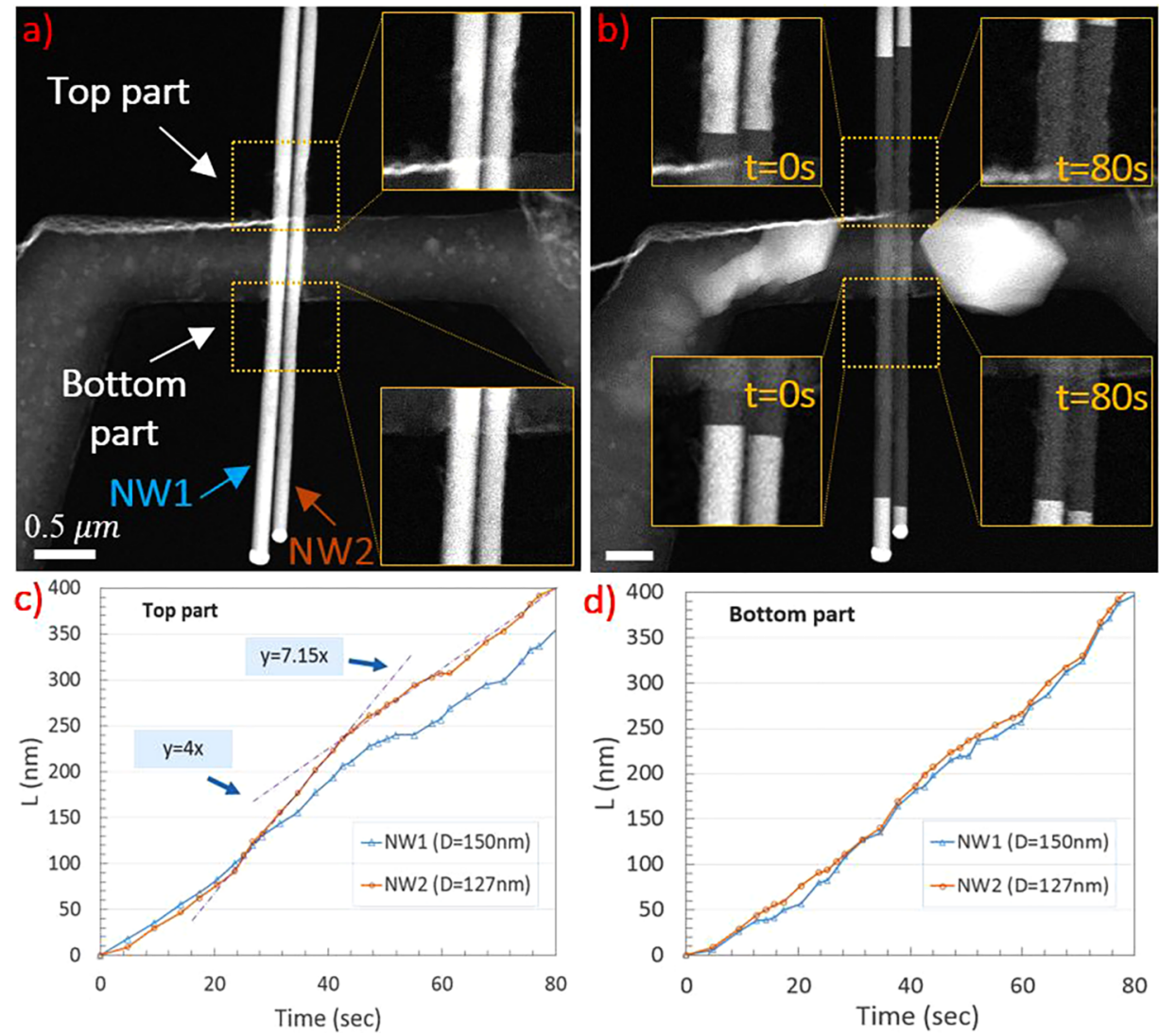

Figure 2. Image sequence extracted from HAADF STEM SI $\mathrm{M}_{4}, H_{\mathrm{a}}$. (a) The sample before reaction initiation. Insets show higher magnifications of NW parts just above and below the heater electrode. (b) The sample after the exchange reaction. Insets show the same regions as in a at different moments. (c) The length of the transformed segment versus time $L$ in the top part of both NWs. The interface was followed starting from an arbitrarily defined moment during the reaction referred to as $t=0$ when the reaction interface had entered both NWs. (d) $L$ versus time for the bottom part of the NWs.

also used for in situ high-angle annular dark-field (HAADF) STEM.

Results. In Figure 1, several heating experiments are shown: heating using direct Joule heating in a metal line on the $\mathrm{Ge}$ NW, that we will call $H_{\mathrm{a}}$ (Figure 1a) and membrane-substrate Joule heating using a DENSsolution heater chip, $H_{\mathrm{b}}$ (Figure $1 \mathrm{~b}, \mathrm{c})$ at 250 and $330{ }^{\circ} \mathrm{C}$, respectively. TEM bright-field (BF) movies of the $\mathrm{Al}-\mathrm{Ge}$ exchange using both heating techniques are shown in Supporting Information (SI) videos SI $\mathrm{M}_{1}-H_{a}$, SI $\mathrm{M}_{2}-H_{\mathrm{b}}\left(250{ }^{\circ} \mathrm{C}\right)$, and SI $\mathrm{M}_{3}-\mathrm{H}_{\mathrm{b}}\left(330{ }^{\circ} \mathrm{C}\right)$.

The images extracted from these respective experiments (SI $\mathrm{M}_{1}$, SI $\mathrm{M}_{2}$, SI $\mathrm{M}_{3}$ ) are shown in Figure 1 . As can be noticed from Figure $1 \mathrm{a}-\mathrm{c}$, the contrast change in the $\mathrm{Ge} \mathrm{NW}$ in $\mathrm{BF}$ images indicates the metal intrusion in the NWs, where a darker contrast is present in the more heavy Ge NW part, and a brighter contrast in the part where $\mathrm{Al}$ has entered. However, due to diffraction contrast, this contrast can be reversed (for example, in the NW marked "Side 3" in SI $\mathrm{M}_{2}$ ).

In SI $\mathrm{M}_{1}-H_{\mathrm{a}}$ (acceleration 2.5 times), we can see a more light gray contrast propagating symmetrically outward from underneath the Al contact in both sides of the NW. Propagation starts first in the left part of the NW (visible underneath the thinner part of the $\mathrm{Al}$ contact) and $27 \mathrm{~s}$ later propagation is also visible in the right part of the NW. During the experiment contrast changes can be observed in the $\mathrm{Al}$ metal contact, as grains in the metal change shape and size due to the temperature and/or the current. At $1 \mathrm{~min} 16 \mathrm{~s}$, the right part of the $\mathrm{NW}$ is entirely converted to $\mathrm{Al}$ (as we will demonstrate below by chemical mapping). In SI $\mathrm{M}_{2}-H_{\mathrm{b}}(250$ ${ }^{\circ} \mathrm{C}$ ) (acceleration 3.5 times), we can see the reaction interface propagating at three locations in the very bend NW. In $\mathrm{SI} \mathrm{M}_{3}-$ $H_{\mathrm{b}}\left(330{ }^{\circ} \mathrm{C}\right)$ (acceleration 3.5 times), the reaction interface first extends symmetrically into both the larger and smaller diameter NW. However, rapidly the interface advances much faster in the large diameter NW. We can observe that the interface is mostly well-defined and straight but can also be curved during a short time interval.

To investigate the kinetics of the metal intrusion, we followed the progress of the reaction interface as a function of time, where $L$ is the distance the reaction interface has traveled. Three different examples of these traces are presented in Figure 1, where both $H_{a}$ and $H_{b}$ heating techniques were used. The shown traces were realized by $H_{\mathrm{a}}$ at $V_{\text {heat }}=0.575 \mathrm{~V}$ and by $H_{\mathrm{b}}$ at 250 and $330{ }^{\circ} \mathrm{C}$, respectively. In Figure 1a,d, we see that the propagation speed is faster in $L_{\text {side2 }}$ (the right part of the NW) where the NW diameter is smaller with respect to $L_{\text {sidel }}$. Figure $1 \mathrm{~b}$ shows TEM images of a heated sample at 250 ${ }^{\circ} \mathrm{C}$ where the propagation was followed only in the curved NW ( $L_{\text {side1 }}, L_{\text {side2 }}$, and $\left.L_{\text {side3 }}\right)$, since in the straight $\mathrm{NW}\left(L_{\text {side4 }}\right)$ the interface position was not well visible (presence of diffraction contrast). The plot describing the evolution of the interface as a function of time in the different sides of the curved NW at $250{ }^{\circ} \mathrm{C}$ is presented in Figure 1e, showing the evolution of the interface in the three NW sides. From the plot in Figure 1e, we see clearly the length $L_{\text {side1 }}<L_{\text {side3 }}<L_{\text {side2 }}$ where the NW diameters are $d_{\mathrm{NW} 3}<d_{\mathrm{NW} 2}<d_{\mathrm{NW} 1}$, so the fastest propagation is 

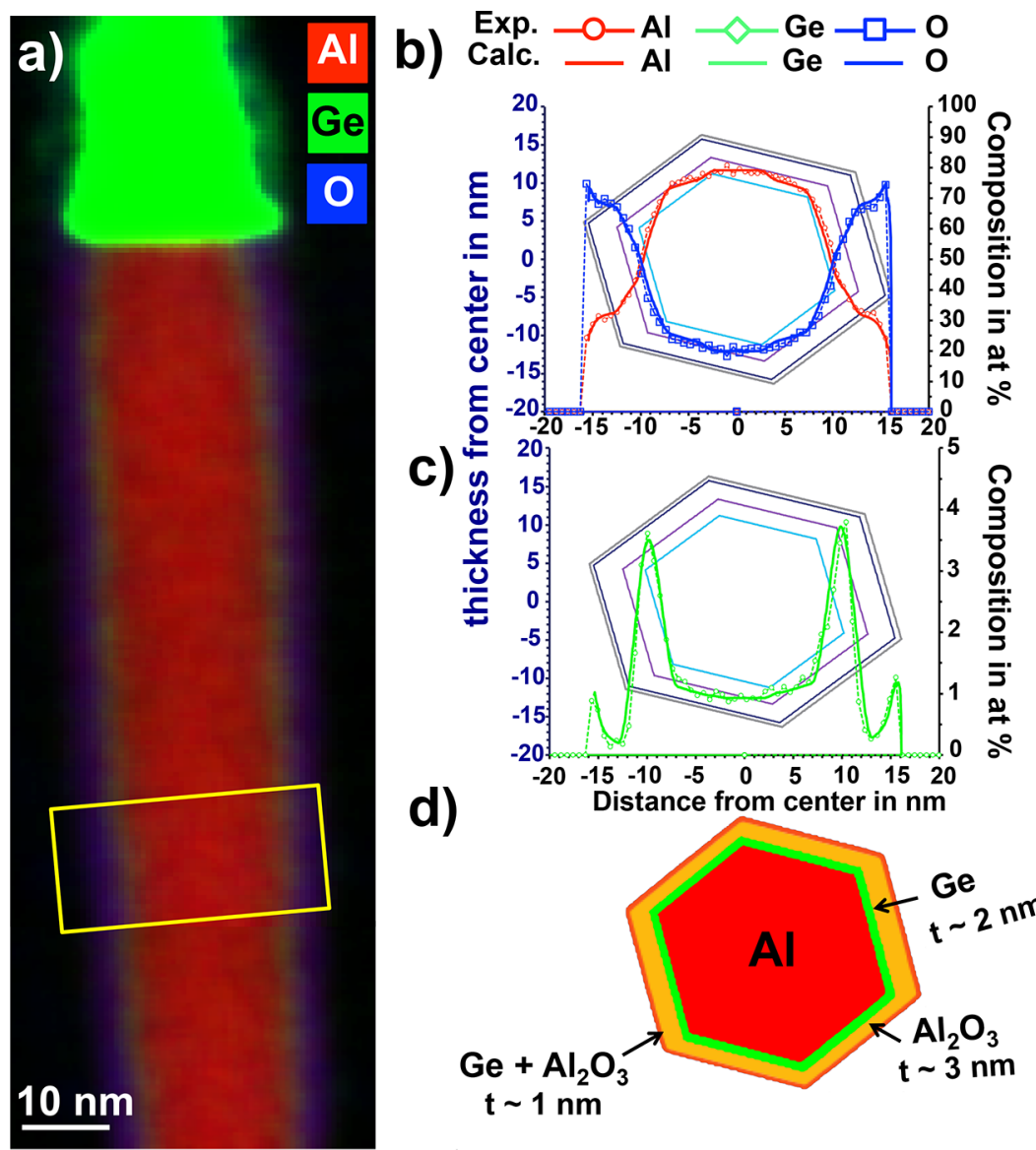

Figure 3. EDX quantification (line scan and hypermap) of different elements (O (blue), $\mathrm{Al}$ (red), Ge (green)) in the $\mathrm{NW}$ after an $H_{\mathrm{a}}\left(V_{\text {heat }}=0.575\right.$ V) experiment. (a) EDX hypermap on the NW after an $H_{\mathrm{a}}$ heating experiment indicating the different elements (O (blue), $\mathrm{Al}(\mathrm{red}), \mathrm{Ge}(\mathrm{green})$ ). $(\mathrm{b}, \mathrm{c})$ Line profiles obtained along the exchanged, lower part defined by the yellow box of the NW where both average concentration (atom \%) and local thickness profiles along the NW cross-section are determined using a quantitative 3D chemical reconstruction model. (d) Schematic representing the chemical reconstruction of the NW cross-section.

observed in the intermediate diameter part of the NW, while lower but similar propagation speeds are observed both in the thicker and thinner part of the same NW. In Figure 1c, TEM images of two Ge NWs contacted by the same $\mathrm{Al}$ metal line are shown before and after heating at $330{ }^{\circ} \mathrm{C}$. The propagation front was followed as a function of time only in the larger diameter NW, since the reaction interface was not very visible in the small diameter NW during the heating experiment. All samples heated using $H_{\mathrm{a}}$ or $H_{\mathrm{b}}$ at low temperature (250-330 ${ }^{\circ} \mathrm{C}$ ) show a parabolic growth behavior and were well fitted using the general equation describing diffusion given by ${ }^{30}$

$$
L=\sqrt{2 D t}
$$

where $L$ is the transformed segment length in nanometers, $D$ is the metal diffusion constant $\left(\mathrm{nm}^{2} / \mathrm{s}\right)$, and $t$ is time in seconds. The propagation speed varies from one NW to another even for propagation in different parts of the same NW and, as can be observed in Figure 1d,e, the propagation speed appears to be influenced by the NW diameter but not exclusively. In general, using observations made on many samples (also using ex situ heating), we observe that the propagation is often faster in the smaller diameter NW. Similar results were obtained by $\mathrm{Kral}$ et $\mathrm{al}^{25}$ where they attest that the $\mathrm{Al}-\mathrm{Ge} \mathrm{NW}$ exchange is size dependent, however, their graph showing propagation speed as a function of NW diameter is characterized by a large scatter of data points, which is very similar to our results. It should be noted that in Kral et al. ${ }^{25}$ no in situ experiments were performed, therefore, observed propagation speeds can be interpreted correctly only if the reaction initiates in all NWs simultaneously, which we know is unlikely and underlines the importance of in situ experiments. Therefore, it appears that the metal intrusion growth rate is often faster in thinner NWs but can also be influenced by other parameters removing the effect of size, as observed in Figure 1e where the NW part with the intermediate diameter showed the fastest propagation. Since the studied NW in Figure le exhibits a strong bending, we speculate that strain is one of the parameters that can influence the reaction speed. It was also observed in movie SI $\mathrm{M}_{3}-\mathrm{H}_{\mathrm{b}}\left(330{ }^{\circ} \mathrm{C}\right)$ that the propagation in the thinner $\mathrm{NW}$ advances much slower than in the large NW.

As another example, the HAADF-STEM movie SI $\mathrm{M}_{4}-\mathrm{H}_{\mathrm{a}}$ shows high-angle annular dark-field STEM of two NWs heated using the $H_{\mathrm{a}}$ technique propagating side by side. Their respective diameters are 150 and $127 \mathrm{~nm}$. The experiment was carried out using varying heating current, therefore we cannot interpret the kinetics of the reaction looking at the propagation length $L$ as a function of time, however we can compare the propagated lengths in the two different NWs and compare the propagation into the upper part of the NWs, that we call "top part" and into the bottom part. Figure 2 shows images extracted from movie SI $\mathrm{M}_{4}-\mathrm{H}_{\mathrm{a}}$ and plots the location of the reaction interface in both NWs as a function of time. Figure 2a 
shows the sample prior to the in situ Joule heating experiment. The insets show that in the top part of the NWs located just above the heater electrode the NW surface is locally rough (presence of contrast variations on the NW) and the thinner NW2 also has a region where the diameter is locally reduced, while the NW surfaces have no such roughness in the NW regions below the heater electrode (smooth contrast on the $\mathrm{NW}$ ). Figure $2 \mathrm{~b}$ shows the sample at the end of the Joule heating experiment, and the insets show the reaction interface both in the top part and bottom part of the NWs at two moments during the experiment where $t=0$ indicates the moment where we start to follow the reaction interface that is followed during $80 \mathrm{~s}$. We see that the reaction interface has first entered in the thinner diameter NW2. Figure 2c,d shows the length the reaction interface has traveled during $80 \mathrm{~s}$ in both NWs in the top part and bottom part of the NWs, respectively. We observe that in the top part of the NWs the reaction speed is first similar in both NWs during around $20 \mathrm{~s}$, but then the reaction speeds up at the thinner location in NW2, Figure 2c. The reaction interface speed recovers to approximately the original value in NW2 when the reaction interface has passed the thinner region. In the bottom part of the NWs, we find very similar reaction speeds in both NWs, Figure $2 \mathrm{~d}$. In this experiment, we see that the reaction interface advances first out from the contact into the thinner NW but then very similar reaction speeds are observed in both NWs. Yet, at the thinner location in NW2 above the heater electrode, the reaction advances faster. We can conclude that indeed the influence of the NW diameter on the reaction speed is ambiguous and that we truly need in situ measurements to better understand the delicate interplay between NW size and potential other factors such as surface roughness (potentially related with surface defects) and strain.

Interestingly, it can be observed in movie SI $\mathrm{M}_{4}-\mathrm{H}_{\mathrm{a}}$ that the reaction starts to occur in multiple nucleation points underneath the $\mathrm{Al}$ metal line. During the $H_{\mathrm{b}}$ heating experiment at $250{ }^{\circ} \mathrm{C}$, the reaction did not start in the thicker NW part of $L_{\text {side4 }}$. Therefore, the heating was increased to 400 ${ }^{\circ} \mathrm{C}$ with the aim to activate the metal intrusion in the NW. As shown in Figure S1, we find that the reaction interface proceeds by large steps at this higher temperature.

These different formed segments heated using Joule heating techniques were chemically and structurally studied in order to investigate the formed heterostructure in the reacted segment. A high-resolution TEM (HRTEM) analysis and preliminary EDX results have been presented in a previous work ${ }^{25}$ and they showed a complete transformation of the Ge segment to a monocrystalline $\mathrm{Al}$ segment. Here we further investigate the formed heterostructure using ex situ energy dispersive X-ray spectroscopy (EDX) analyses performed on reacted samples using both $H_{\mathrm{a}}$ and $H_{\mathrm{b}}$ heating techniques with much improved $\mathrm{X}$-ray count statistics. This allows using a 3D chemical reconstruction model proposed by Rueda et al. ${ }^{31}$ to provide a reconstruction of the reacted segment cross-section and to determine the proportions of different elements present in the heterostructure.

These analyses were performed in an ultranarrow gap Fischione tomography sample holder, which allows a large angle for signal detection contrary to the DENSsolution sample holder where the six pins mask an important amount of the emitted X-rays. Figure 3 represents the EDX hypermap of the sample heated using $H_{a}$ at $V_{\text {heat }}=0.475 \mathrm{~V}$ with the corresponding $3 \mathrm{D}$ cross-section reconstruction using the EDX model, ${ }^{31}$ adapted to objects with a hexagonal cross-section. Figure $3 b-d$ illustrates the distribution of the different layers forming the NW cross-section. The dashed curves in Figure 3 b,c with symbols (red -- $\bigcirc--$, green -- $\backslash$--, blue -- $\square--$ ) are the atomic concentrations of $\mathrm{Al}, \mathrm{Ge}$, and $\mathrm{O}$, respectively, deduced directly from the net experimentalX-ray intensity of each element using the zeta factor method ${ }^{32}$ and the (red line, green line, blue line) solid curves are the calculated concentration profiles using an hexagonal model of the NW cross-section. We find that the NW cross-section can be modeled by four imbricated hexagons (see Figure $3 \mathrm{~d}$ ): a thick pure $\mathrm{Al}$ core with a thickness of $17.5 \mathrm{~nm}$ surrounded by a shell of pure $\mathrm{Ge}$ of $\sim 2$ $\mathrm{nm}$, surrounded by an $\mathrm{Al}_{2} \mathrm{O}_{3}$ layer of $\sim 3 \mathrm{~nm}$ and covered by a Ge containing $\mathrm{Al}_{2} \mathrm{O}_{3}$ shell of $\sim 1 \mathrm{~nm}$. This cross-section model reproduces perfectly the experimental concentration profiles extracted directly from the EDX hypermap perfectly. This analysis confirms the hypothesis that Ge is entirely replaced by $\mathrm{Al}$ in the reacted part of the $\mathrm{NW}$ creating an $\mathrm{Al} / \mathrm{Ge}$ heterostructure. A Ge containing shell is observed around the core of pure $\mathrm{Al}$, indicating that $\mathrm{Ge}$ is diffusing back into the metal contact by a surface diffusion process. Moreover, we verified using electron diffraction that the created $\mathrm{Al} \mathrm{NW}$ is monocrystalline and has the usual face-centered cubic structure (fcc), see Supporting Information (SI.II). Furthermore, the EDX analysis was extended to the $\mathrm{Al}$ pad (see Figure 4),

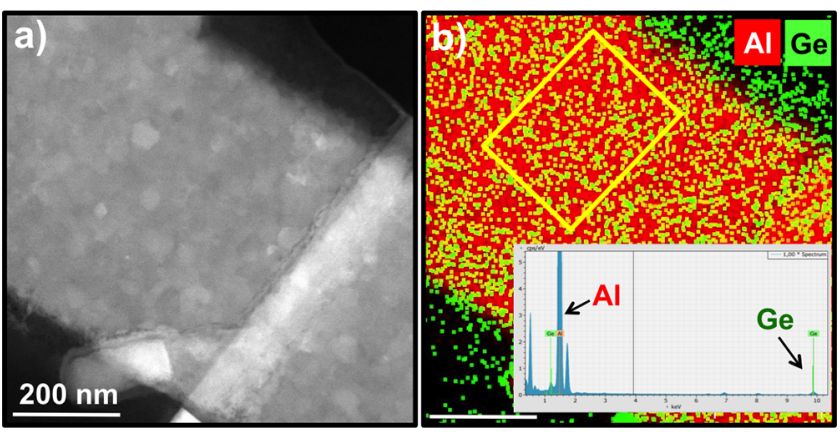

Figure 4. (a) STEM image and (b) EDX hypermap obtained after phase propagation using the $H_{\mathrm{b}}$ heating technique at $380^{\circ} \mathrm{C}$. An EDX spectrum integrated over the boxed region is shown in the inset, demonstrating both $\mathrm{Al}$ and $\mathrm{Ge} \mathrm{X}$-ray lines in the $\mathrm{Al}$ metal.

revealing the presence of $\mathrm{Ge}$ atoms, most likely formerly constituting the NW. This experiment shows the favorable incorporation of $\mathrm{Ge}$ atoms in the polycrystalline $\mathrm{Al}$ pad (see hypermap with the respective EDX spectrum in Figure 4b).

Discussion. In the following, we combine both kinetic and structural analysis results to get a better understanding of the replacement of $\mathrm{Ge}$ by $\mathrm{Al}$ in a NW.

We first fit the kinetic data from Figure $1 d-f$ with eq 1 in order to evaluate the difference in the reaction speed that is reflected in the fit parameter between the different experimental conditions. These results are summarized in Table 1 . We can see from this analysis that very similar propagation speeds can be obtained using both heating techniques, indicating that the heating temperature we reach in $H_{\mathrm{a}}$ experiments is similar to the temperature we apply in temperature calibrated $H_{\mathrm{b}}$ experiments (in the $250-330{ }^{\circ} \mathrm{C}$ range). Recently several papers ${ }^{9,10,17,33,34}$ have presented a diffusion model describing such a solid-state reaction in semiconducting NWs. We have adapted this model. ${ }^{29}$ In this model, four different regimes can govern the incorporation of 
Table 1. Summary of Different Experiments Performed on Aluminum-Germanium Samples Using Both $H_{\mathrm{a}}$ and $H_{\mathrm{b}}$ Heating Techniques at Low Temperature

\begin{tabular}{|c|c|c|c|c|c|}
\hline \multicolumn{3}{|c|}{ Heating Temperature Number of NW } & Diameter & \multicolumn{2}{|c|}{ Curve Behavior Fit Coefficient ( $\mathrm{nm} / \mathrm{sec}^{0.5}$ ) } \\
\hline $\mathbf{H}_{\mathbf{a}}$ & $V_{\text {heat }}=0,575$ volt & $1 \mathrm{NW}$ & $D_{1}=20.5 \mathrm{~nm} ; D^{\prime}{ }_{1}=15-13 \mathrm{~nm}$ & Square root & $B_{1}=22,45 ; B_{2}=99$ \\
\hline $\mathbf{H}_{\mathrm{b}}$ & $250^{\circ} \mathrm{C}$ & 1 NW & $D_{1}=33.5 \mathrm{~nm} ; D_{2}=29.6 \mathrm{~nm} ; D_{3}=26.5 \mathrm{~nm}$ & Square root & $B_{1}=118 ; B_{2}=247 ; B_{3}=127$ \\
\hline $\mathbf{H}_{\mathrm{b}}$ & $330^{\circ} \mathrm{C}$ & 1 NWs & $D_{1}=50 \mathrm{~nm} ; D_{1}^{\prime}=26 \mathrm{~nm}$ & Square root & $B_{1}=17.71 ; B_{2}=$ can't be fit \\
\hline
\end{tabular}

metal atoms in a semiconducting NW during a thermal annealing. We have described this model in detail, ${ }^{29}$ here we just present briefly the four potential rate limitation steps and how the converted region $\mathrm{L}$ varies as a function of time $t$ and $R$ $\mathrm{NW}$ radius.

We can see from Table 2 that if volume diffusion is the rate limiting step, $L$ will be independent of the NW radius $R$.

Table 2. Summary of the Different Regimes Governing the Metal Propagation 29

$\begin{array}{cl}\text { germanide growth regimes } & L \\ \text { metal reservoir limited } & \sim R^{-1} t \\ \text { interfacial exchange limited } & \sim t \text { (independent of } R \text { ) } \\ \text { volume diffusion limited } & \sim \sqrt{t} \\ & (\text { independent of } R) \\ \text { surface diffusion limited } & \sim\left(\sqrt{\frac{t}{R}}\right)\end{array}$

However, if surface diffusion is the rate limiting step, $L$ will vary as a function of $R^{-1}$.

As we explained above, the influence of the NW diameter on the propagation speed is not systematic throughout our data and all kinetic plots at these different low temperatures evidence a square root behavior (see Figure $1 \mathrm{~d}-\mathrm{f}$ ).

This indicates that the rate limiting step of the reaction propagation is a diffusion process, however it is not clear if the rate limiting step only involves volume diffusion, or could be influenced by surface diffusion as well. Therefore, we use the parabolic growth law presented in eq 1 to fit the kinetic data and extract a diffusion coefficient without taking a size effect into account and summarize the resulting average diffusion coefficients in Table 3 .

\section{Table 3. Measured Diffusion Coefficients}

$\begin{array}{llc} & \text { heating } & D\left(\mathrm{~cm}^{2} / \mathrm{s}\right) \\ H_{\mathrm{b}} & T=330{ }^{\circ} \mathrm{C} & 1.56 \times 10^{-12} \\ H_{\mathrm{b}} & T=250^{\circ} \mathrm{C} & 1.51 \times 10^{-10}\end{array}$

We examine the $\mathrm{Al}-\mathrm{Ge}$ phase diagram and consider the substantially different diffusion behaviors of $\mathrm{Ge}$ in $\mathrm{Al}$ and vice versa. $^{35,36}$ The binary $\mathrm{Ge}-\mathrm{Al}$ phase diagram is of the simple eutectic type with no intermetallic phase formation. The melting points of $\mathrm{Al}$ and $\mathrm{Ge}$ are 660 and $938^{\circ} \mathrm{C}$, respectively, and the eutectic point is located at a Ge composition of about 29.5 atom \% with solid to liquid transition at $350{ }^{\circ} \mathrm{C}$. $\mathrm{Al}$ shows a solubility of 0.5 atom $\%$ in $\mathrm{Ge}$, while $\mathrm{Al}$ can contain up to 1.5 atom \% of Ge.

As listed in Table 4, the diffusion constants for both $\mathrm{Ge}$ and $\mathrm{Al}$ in $\mathrm{Al}$ at $330{ }^{\circ} \mathrm{C}$ are considerable, that is, $10^{14}$ times larger than in Ge.

Thus, when the heating starts to provide enough energy, Ge atoms diffuse from the interface into the $\mathrm{Al}$ pad, diffusing on the $\mathrm{Al}$ segment in a small shell of $\sim 2 \mathrm{~nm}$ by surface diffusion, as observed by EDX, and we speculate that $\mathrm{Al}$ is supplied to the reaction interface by self-diffusion, leading to an exchange of $\mathrm{Al}$ and $\mathrm{Ge}$ atoms, where $\mathrm{Al}$ atoms start to replace $\mathrm{Ge}$ atoms in the contacted NW.

The diffusion coefficient found at $330{ }^{\circ} \mathrm{C}$ is comparable to the bulk Al self-diffusion at $330{ }^{\circ} \mathrm{C}$ presented in Table 4, supporting the hypothesis that the reaction is limited by $\mathrm{Al}$ self-diffusion. A schematic description of the observed diffusion behaviors of both $\mathrm{Al}$ and $\mathrm{Ge}$ is shown in Figure 5. The diffusion coefficient at $250{ }^{\circ} \mathrm{C}$, is much higher compared to the $\mathrm{Al}$ self-diffusion from literature. ${ }^{35} \mathrm{We}$ speculate that this high value is due to the NW curvature.

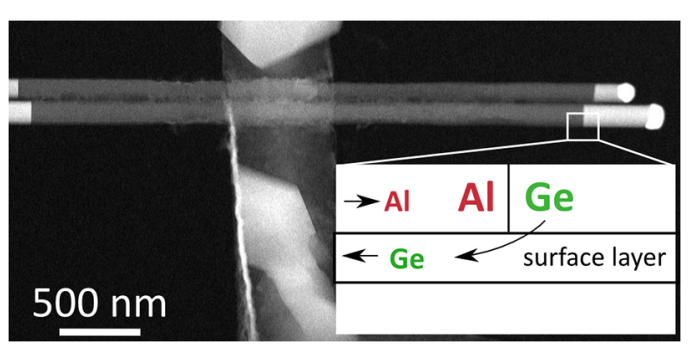

Figure 5. HAADF STEM image combined with a schematic showing the proposed mechanism. Ge atoms can diffuse to the $\mathrm{Al}$ reservoir through a surface channel and $\mathrm{Al}$ atoms are supplied to the reaction interface by volume diffusion.

We speculate that the rate limiting step at high temperature, where stepwise growth was observed, is related to a trapping/ detrapping mechanism of the reaction interface at the NW surface, potentially related to a very local surface defect that is difficult to observe in TEM. It should be noted that the exchange reaction also took place when the whole structure was covered by $\mathrm{Al}_{2} \mathrm{O}_{3}$, indicating that even with a shell on the

Table 4. Activation Energy and Diffusion Coefficients ${ }^{35,36}$ for Ge and Al, and Resulting Diffusion Constant at the Annealing Temperature of $330^{\circ} \mathrm{C}$

$\begin{array}{lccc} & \text { aluminum in aluminum } & \text { germanium in aluminum } & \text { aluminum in germanium } \\ E_{\mathrm{a}}(\mathrm{kJ} / \mathrm{mol}) & 123.5 & 121.3 & 332.8 \\ D_{0}\left(\mathrm{~cm}^{2} / \mathrm{s}\right) & 0.137 & 0.48 & 1000 \\ D 330^{\circ} \mathrm{C}\left(\mathrm{cm}^{2} / \mathrm{s}\right) & 2.71 \times 10^{-12} & 1.47 \times 10^{-11} & 1.43 \times 10^{-26}\end{array}$


Ge NW, Ge can still diffuse at the interface of $\mathrm{Ge}$ and $\mathrm{Al}_{2} \mathrm{O}_{3}$. Remarkably, in the remaining Ge NW segment no $\mathrm{Al}$ contamination can be detected, which is attributed to the extremely low diffusion coefficient of $\mathrm{Al}$ in $\mathrm{Ge}$. Gold was used as catalyst for NW growth. In Si NWs, both gold clusters on the NW surface ${ }^{37}$ as well as gold atoms in the NW volume ${ }^{38}$ have been observed. For Ge NWs, it is currently not known if gold can incorporate in a similar way. The NWs in the present study did not have gold clusters on their surface; otherwise such clusters would have been clearly visible in the TEM and especially HAADF STEM images (as shown, for example, in Figure 2). Therefore, we do not think there was interference due to the presence of gold with the exchange reaction. Indeed, for integration into devices the gold catalyst potentially has to be removed

In summary, this work presents a detailed in situ TEM study of the solid-state reaction via direct Joule heating $H_{a}$ and controlled temperature $H_{\mathrm{b}}$ heating experiments. A strong asymmetry in the diffusion behavior of $\mathrm{Al}$ and $\mathrm{Ge}$ enables the formation of metal/semiconductor NW heterostructures via thermal annealing. Aluminum-germanium heterostructures are formed at low temperatures starting from $250{ }^{\circ} \mathrm{C}$. The kinetic results at low temperature indicate that the $\mathrm{Al} / \mathrm{Ge} \mathrm{NW}$ propagation is governed by the $\mathrm{Al}$ self-diffusion through the created $\mathrm{Al}$ segment. Ge diffuses through a surface channel to the $\mathrm{Al}$ reservoir, as observed by EDX, and does not noticeably influence the propagation rate. The formation of single crystalline $\mathrm{Al}$ NWs via these both thermal annealing techniques was confirmed by quantitative EDX analysis, revealing a double core-shell structure, with an $\mathrm{Al}$ core covered by a thin layer of Ge with an estimated thickness of $2 \pm 0.2 \mathrm{~nm}$, covered by an $\mathrm{Al}_{2} \mathrm{O}_{3}$ shell with another region of low $\mathrm{Ge}$ concentration at its surface with a thickness around $1 \mathrm{~nm}$. Additional characterization by electron diffraction demonstrated the monocrystallinity of the $\mathrm{Al}$ segment. Comparing the reaction kinetics of both heating techniques indicates that similar low temperatures as used in $H_{\mathrm{b}}$ experiments can be obtained by $H_{\mathrm{a}}$ heating, which gives the possibility of using only electrical control to both fabricate and electrically characterize short channel metal oxide semiconductor field effect transistors down to sub-10 nm length scales, independent of the spatial resolution of an lithography process. We demonstrated that in situ TEM is a powerful and indispensable tool to better understand and control the promising material combination of $\mathrm{Al}$ and $\mathrm{Ge}$.

\section{ASSOCIATED CONTENT}

\section{S Supporting Information}

The Supporting Information is available free of charge on the ACS Publications website at DOI: 10.1021/acs.nanolett.8b05171.

TEM bright field movie $\mathrm{M}_{1}-\mathrm{H}_{\mathrm{a}}$ (AVI)

TEM bright field movie $\mathrm{M}_{2}-\mathrm{H}_{\mathrm{b}}\left(250^{\circ} \mathrm{C}\right)$ (AVI)

TEM bright field movie $\mathrm{M}_{3}-\mathrm{H}_{\mathrm{b}}\left(300{ }^{\circ} \mathrm{C}\right)$ (AVI)

HAADF-STEM movie $\mathrm{M}_{4}-\mathrm{H}_{\mathrm{a}}$ (AVI)

Figure S1: Heating experiment at $400{ }^{\circ} \mathrm{C}$ and position of the interface $(L)$ as a function of time $(t)$. Figure $S 2$ : Diffraction analysis of exchanged Al NW(PDF)

\section{AUTHOR INFORMATION}

\section{Corresponding Author}

*E-mail: martien.den-hertog@neel.cnrs.fr. Phone: +33 (0)4 76881045 .

\section{ORCID}

Khalil El hajraoui: 0000-0002-7627-6981

Minh Anh Luong: 0000-0002-0876-2400

Alois Lugstein: 0000-0001-5693-4775

Pascal Gentile: 0000-0002-1547-4247

Martien Den Hertog: 0000-0003-0781-9249

Notes

The authors declare no competing financial interest.

\section{ACKNOWLEDGMENTS}

Financial support from the ANR JCJC COSMOS (ANR-12JS10-0002), the French CNRS and CEA is acknowledged. We acknowledge support from the Laboratoire d?excellence LANEF in Grenoble (ANR-10-LABX-51-01). We benefited from the access to the technological platform NanoCarac of CEA-Minatech and Nanofab from institute NEEL, Grenoble. Furthermore, the authors from Grenoble and Vienna received traveling support from the AMADEUS/CampusFrance program. This project has received funding from the European Research Council (ERC) under the European Union's Horizon 2020 research and innovation programme (Grant Agreement 758385).

\section{REFERENCES}

(1) Duan, X.; Huang, Y.; Cui, Y.; Wang, J.; Lieber, C. M. Nature 2001, 409, 66-69.

(2) Joyce, H. J.; Gao, Q.; Hoe Tan, H.; Jagadish, C.; Kim, Y.; Zou, J.; Smith, L. M.; Jackson, H. E.; Yarrison-Rice, J. M.; Parkinson, P.; Johnston, M. B. Prog. Quantum Electron. 2011, 35, 23-75.

(3) Peng, K.-Q.; Wang, X.; Li, L.; Hu, Y.; Lee, S.-T. Nano Today 2013, 8, 75-97.

(4) Hrkac, G.; Dean, J.; Allwood, D. A. Philos. Trans. R. Soc., A 2011, 369, 3214-3228.

(5) Chou, Y. C.; Wu, W. W.; Cheng, S. L.; Yoo; Myung, N.; Chen, L. J.; Tu, K. N. Nano Lett. 2008, 8, 2194-2199.

(6) Holmberg, V. C.; Collier, K. A.; Korgel, B. A. Nano Lett. 2011, $11,3803-3808$.

(7) Mongillo, M.; Spathis, P.; Katsaros, G.; Gentile, P.; Sanquer, M.; De Franceschi, S. ACS Nano 2011, 5, 7117-7123.

(8) Lin, Y. C.; Chen, Y.; Huang, Y. Nanoscale 2012, 4, 1412-1421.

(9) Yaish, Y. E.; Katsman, A.; Cohen, G. M.; Beregovsky, M. J. Appl. Phys. 2011, 109, 094303.

(10) Ogata, K.; Sutter, E.; Zhu, X.; Hofmann, S. Nanotechnology 2011, 22, 365305.

(11) Wu, Y. T.; Huang, C. W.; Chiu, C. H.; Chang, C. F.; Chen, J. Y.; Lin, T. Y.; Huang, Y. T.; Lu, K. C.; Yeh, P. H.; Wu, W. W. Nano Lett. 2016, 16, 1086-1091.

(12) Lu, K. C.; Wu, W. W.; Ouyang, H.; Lin, Y. C.; Huang, Y.; Wang, C. W.; Wu, Z. W.; Huang, C. W.; Chen, L. J.; Tu, K. N. Nano Lett. 2011, 11, 2753-2758.

(13) Dellas, N. S. Silicide and germanide contacts to silicon and germanium nanowires. Ph.D. Thesis, The Pennsylvania State University, May 2011.

(14) Chiu, C. H.; Huang, C. W.; Chen, J. Y.; Huang, Y. T.; Hu, J. C.; Chen, L. T.; Hsin, C. L.; Wu, W. W. Nanoscale 2013, 5, 5086-5092.

(15) Hsu, S.-C.; Hsin, C.-L.; Huang, C.-W.; Yu, S.-Y.; Wang, C.-W.; Lu, C.-M.; Lu, K.-C.; Wu, W.-W. CrystEngComm 2012, 14, 45704574.

(16) Lu, K. C.; Wu, W. W.; Wu, H. W.; Tanner, C. M.; Chang, J. P.; Chen, L. J.; Tu, K. N. Nano Lett. 2007, 7, 2389-2394.

(17) Chen, Y.; Lin, Y.-C.; Huang, C.-W.; Wang, C.-W.; Chen, L.-J.; Wu, W.-W.; Huang, Y. Nano Lett. 2012, 12, 3115-3120.

(18) Okino, H.; Matsuda, I.; Hobara, R.; Hosomura, Y.; Hasegawa, S.; Bennett, P. A. Appl. Phys. Lett. 2005, 86, 233108.

(19) Burchhart, T.; Lugstein, A.; Hyun, Y. J.; Hochleitner, G.; Bertagnolli, E. Nano Lett. 2009, 9, 3739-3742. 
(20) Wu, Y.; Xiang, J.; Yang, C.; Lu, W.; Lieber, C. M. Nature 2004, 430, 61-65.

(21) Lensch-Falk, J. L.; Hemesath, E. R.; Lauhon, L. J. Nano Lett. 2008, 8, 2669-2673.

(22) Tang, J.; Wang, C. Y.; Hung, M. H.; Jiang, X.; Chang, L. T.; He, L.; Liu, P. H.; Yang, H. J.; Tuan, H. Y.; Chen, L. J.; Wang, K. L. ACS Nano 2012, 6, 5710-5717.

(23) Lin, Y. C.; Lu, K. C.; Wu, W. W.; Bai, J.; Chen, L. J.; Tu, K. N.; Huang, Y. Nano Lett. 2008, 8, 913-918.

(24) Tinani, M.; Mueller, A.; Gao, Y.; Irene, E. A.; Hu, Y. Z.; Tay, S. P. J. Vac. Sci. Technol., B: Microelectron. Process. Phenom. 2001, 19, 376.

(25) Kral, S.; Zeiner, C.; Stöger-Pollach, M.; Bertagnolli, E.; den Hertog, M. I.; Lopez-Haro, M.; Robin, E.; El Hajraoui, K.; Lugstein, A. Nano Lett. 2015, 15, 4783-4787.

(26) Burchhart, T.; Lugstein, A.; Hyun, Y. J.; Hochleitner, G.; Bertagnolli, E. Nano Lett. 2009, 9, 3739-3742.

(27) http://denssolutions.com/products/nano-chip/.

(28) den Hertog, M. I.; González-Posada, F.; Songmuang, R.; Rouviere, J. L.; Fournier, T.; Fernandez, B.; Monroy, E. Nano Lett. 2012, 12, 5691-5696.

(29) El Hajraoui, K. In-situ transmission electron microscopy studies of metal-Ge nanowire solid-state reactions. PhD Thesis, Université de Grenoble, France, https://tel.archives-ouvertes.fr/tel-01645553/file/ main.pdf, 2017.

(30) Nemouchi, F.; Mangelinck, D.; Bergman, C.; Gas, P.; Smith, U. Appl. Phys. Lett. 2005, 86, 041903.

(31) Rueda-Fonseca, P.; Robin, E.; Bellet-Amalric, E.; Lopez-Haro, M.; Hertog, M. D.; Genuist, Y.; André, R.; Artioli, A.; Tatarenko, S.; Ferrand, D.; Cibert, J. Nano Lett. 2016, 16, 1637-1642.

(32) Watanabe, M.; Williams, D. B. J. Microsc. 2006, 221, 89-109.

(33) Katsman, A.; Yaish, Y.; Rabkin, E.; Beregovsky, M. J. Electron. Mater. 2010, 39, 365-370.

(34) Tang, W.; Nguyen, B.-M.; Chen, R.; Dayeh, S. A. Semicond. Sci. Technol. 2014, 29, 054004.

(35) Landolt-Börnstein: Group III Condensed Matter; Beke, D. L., Ed.; Springer: Berlin Heidelberg, 1998; Vol. 33A.

(36) Smithells Metals Reference Book; William, F., Gale, T. C. T., Eds.; Elsevier Science: Dordrecht, The Netherlands, 2003.

(37) den Hertog, M. I.; Rouviere, J.-L.; Dhalluin, F.; Desré, P. J.; Gentile, P.; Ferret, P.; Oehler, F.; Baron, T. Nano Lett. 2008, 8, $1544-1550$.

(38) Allen, J. E.; Hemesath, E. R.; Perea, D. E.; Lensch-Falk, J. L.; Li, Z. Y.; Yin, F.; Gass, M. H.; Wang, P.; Bleloch, A. L.; Palmer, R. E.; Lauhon, L. J. Nat. Nanotechnol. 2008, 3, 168. 